\title{
Difficulties in achieving a sustainable blood supply: report from the first national seminar on blood donation in Lebanon
}

Antoine Haddad, ${ }^{1,2 *}$ Tarek Bou Assi, ${ }^{3,4}{ }^{*}$ Laura Haddad, ${ }^{5}$ Perrine Wakim, ${ }^{6}$ Rita Feghali, ${ }^{7,8}$ Wissam Makki, ${ }^{9}$ Mohammad Haidar, ${ }^{10}$ Yorgui Teyrouz, ${ }^{11}$ Hanadi Samaha, ${ }^{12}$ Tamima Jisr, ${ }^{13}$ Christian Haddad, ${ }^{14}$ Elizabeth Baz,,${ }^{15}$ Berthe Hachem, ${ }^{16}$ Vanda Barakett ${ }^{17}$ and Olivier Garraud ${ }^{1,18}$

\begin{abstract}
${ }^{1}$ EA3064, Faculty of Medicine of Saint-Etienne, University of Lyon, Saint-Etienne, France (Correspondence to: Antoine Haddad: anthadd@gmail.com). ${ }^{2}$ Department of Clinical Pathology and Blood Banking, Hopital du Sacre Coeur, Baabda, Lebanon. ${ }^{3}$ Department of Laboratory Medicine, Psychiatric Hospital of the Cross, Jaledib, Lebanon. ${ }^{4}$ Department of Laboratory Medicine and Blood Bank, Saint Joseph Hospital, Dora, Lebanon. ${ }^{5}$ Faculty of Medicine, University of Balamand, Beirut, Lebanon ${ }^{6}$ ESA Business School, Hamra, Lebanon. ${ }^{7}$ Department of Laboratory Medicine and Blood Bank, Rafic Hariri University Hospital, Beirut, Lebanon. ${ }^{8}$ Lebanese Red Cross, Beirut, Lebanon. ${ }^{9}$ Department of Laboratory Medicine and Blood Bank, Military Hospital, Beirut, Lebanon. ${ }^{10}$ Department of Laboratory Medicine and Blood Bank, Bahman Hospital, Beirut, Lebanon. "Donner Sang Compter, Beirut, Lebanon. ${ }^{12}$ Department of Laboratory Medicine and Blood Transfusion Unit, Saint George Hospital-University Medical Center, Beirut, Lebanon. ${ }^{13}$ Department of Laboratory Medicine and Blood Bank, Makassed General Hospital, Beirut, Lebanon. ${ }^{14}$ Department of Laboratory Medicine and Blood Bank, Centre Hospitalier Universitaire Notre Dame de Secours, Jbeil, Lebanon. ${ }^{15}$ Department of Blood Bank, American University of Beirut, Lebanon. ${ }^{16}$ Department of Blood Bank, Middle East Institute of Health, Bsalim, Lebanon. ${ }^{17}$ Department of Laboratory Medicine, Hôtel Dieu de France Hospital, Beirut, Lebanon. ${ }^{18}$ Institut National de la Transfusion Sanguine, Paris, France.

${ }^{*}$ Equal contributors.
\end{abstract}

\begin{abstract}
Background: Lebanon has a decentralized/fragmented transfusion system. The current blood supply does not meet the World Health Organization target of achieving 100\% voluntary non-remunerated blood donation (VNRD). There are currently 3 types of donors/donations in Lebanon: replacement/family donations (70-75\%), VNRD (20-25\%), and compensated donations (5-10\%). Remunerated donations are illegal.

Aims: This report summarizes the content of presentations given during the first World Blood Donor Day seminar in Lebanon in June 2017. The aim is to describe the current Lebanese blood supply system and the major road blocks and to suggest practical recommendations that may assist in achieving 100\% VNRD.

Methods: The content of presentations given during the first World Blood Donor Day seminar in Lebanon in June 2017 were summarized.

Results: The seminar was attended by all major stakeholders involved in transfusion medicine (Lebanese National Committee of Blood Transfusion, Hospital Blood Banks directors, Lebanese Army Blood Bank, Lebanese Red Cross and Donner Sang Compter).

Conclusions: The Ministry of Public Health should focus on performing regular audits regarding the implementation of national guidelines. There is a need for a national blood supply committee, unifying all stakeholders in the transfusion and donation fields. Transfusion medicine should be declared by law as a public health issue and considered a priority for patient safety.

Keywords: Blood supply, Blood donation, voluntary non-remunerated donors, Lebanon

Citation: Haddad A; Bou Assi T; Haddad L; Wakim P; Feghali R; Makki W; et al. Difficulties in achieving a sustainable blood supply: report from the first national seminar on blood donation in Lebanon. East Mediterr Health J. 2020;26(6):736-743. https://doi.org/10.26719/emhj.19.070.

Received: 16/05/18; accepted: 03/12/18

Copyright (C) World Health Organization (WHO) 2020. Open Access. Some rights reserved. This work is available under the CC BY-NC-SA 3.o IGO license (https://creativecommons.org/licenses/by-nc-sa/3.o/igo).
\end{abstract}

\section{Introduction}

This study summarizes the content of the presentations that occurred during the first World Blood Donor Day seminar in Lebanon, held 14 June 2017 at one of the major health care facilities in Beirut-Hôpital du Sacré Coeur. This seminar was under the patronage of the Lebanese National Committee of Blood transfusion (LNCBT) during which all major stakeholders in transfusion medicine analysed the various difficulties occurring in the field of blood supply.

Blood is essential in assisting and providing the optimal patients' health care (1). In spite of many advances in immuno-haematology, blood components are still produced from human origin and thus considered as a rare source. In many high-income countries, patient blood management and optimal use of blood programmes reduced the red blood cell components demand and supply (2). Whereas low and middle-income countries are facing increased need in blood components as more patients require transfusion due to ageing, development of surgical and specific medical care procedures and to high prevalence of haemoglobinopathies in certain regions (3). Amongst these countries, Lebanon has a decentralized/fragmented blood transfusion system and the blood donation is mainly hospital based with a small part performed by nongovernmental organizations, either alone (Lebanese Red Cross) or in association with hospital blood banks (Donner Sang Compter Association, etc.). Thus, blood supply is mainly based on replacement/ family donation (around 75\%) and cannot meet the WHO request. Indeed, WHO recommended regularly that blood supply in each country entirely should be based on voluntary non-remunerated donors (VNRD) because this type of donation is the most sustainable and safest for both donors and patients (4). 
Effectively, a volunteer-regular donor is committed to ensure blood sustainability and possess enough knowledge to recognize risky behaviours that can potentially cause harm for self and recipients. This is very critical especially in transfusion systems that do not perform nucleic acid testing, which is the case in most Middle Eastern countries including Lebanon (5). In fact, each country has its own blood transfusion system and blood donation vary from what is nearly a national service like the United Arab Emirates, to a completely hospitalbased blood banking system such as Saudi Arabia and Palestine, and mixture of partial unified to hospitalbased blood banking system as in Egypt and Jordan (6). That is why, in the last meetings of the WHO Regional Committee (2009 and 2016) $(7,8)$ members urged Middle Eastern countries to establish and implement a national blood system with well-coordinated blood transfusion activities and to make attempts towards reaching 100\% VNRD in 2020 (7), later postponed to 2025 (8).

Having identified the hurdles and road-blocks preventing the achievement of the WHO goal, Lebanon is still seeking the best strategy/plan to improve its blood supply in the time frame set by the WHO. The seminar had the objective of detailing the currently available Lebanese blood supply system, the major road blocks as listed by the national professionals/experts and suggests practical recommendations for national authorities that could assist them in achieving 100\% VNRD.

\section{The current Lebanese blood transfusion service}

\section{Overview}

Lebanon is characteristically ruled by a liberal economic system that values most private initiative and the right of private property (9). However, it is particularly difficult to set up a public plan to overview transfusion medicine (TM) as the health care system is by essence chiefly within the private sector. As a matter of fact, TM is not considered a "Public Health Affair", in opposition to what WHO recommends (10). Actually, around $83 \%$ of the health care activities take place in private facilities while only $17 \%$ in public ones (11). There are 140 hospital-based blood banks (HBBs); around 60 are licensed by the MoPH of whom only 9 collect more than 4000 units per year and $36 \mathrm{col}-$ lect single donor apheresis platelets (unpublished data $\mathrm{MoPH})$. Each health care facility runs its own HBB, usually integrated in the Department of Clinical Laboratory Medicine or Pathology; HBBs are overseen and under the responsibility of physicians (either clinical pathologists or haematologists) (5), of whom only a minority are specialized in TM. HBBs collect mainly whole blood, process it according to a national standard that comprises universal leukoreduction (in force as of 2013), then proceed to the quality and safety testing according to a national standard (HIV1/2 Ag/Ab, HCV Ab, HBs Ag, Anti-HBc and $P R P)$ and finally establish their own inventory with the $\mathrm{ABO}$ and $\mathrm{RH}: 1$ (RhD) groups; other blood groups are not standard. Patients are then tested in the same department that proceeds to the indirect Coombs (anti-globulin) test and cross-match. Blood products in Lebanon are invoiced as laboratory tests and reimbursed by public and private insurance while patients pay a part of the hospitalization bill. Consequently, the national blood transfusion service is extremely fragmented and decentralized (12).

There are currently in Lebanon three different types of donors/donations in Lebanon: 1) Replacement/family donations are estimated to be around 70 to $75 \%$; (2) VNRDs represents around 20 to $25 \% ; 3$ ) and compensated donations are estimated to be around 5 to $10 \%$ (5). Remunerated donations are officially forbidden by the Lebanese law since 2006; penalty can be put on donors or patients if financial incentive was proved during donor recruitment. However, this law does not specifically mention any third-party payers (13). Thus, theoretically no donors are remunerated but it came to public knowledge that cases of recruited donor remuneration can occur in Syrian or Palestinian refugee camps and in situations when patients outside a defined community have reduced family and friend or relative circles.

\section{The replacement/family donors/HBBs donors}

Replacement/family donors are those who give blood upon request by a member of their own family or community or a friend; thus, replacement donation involves the patient directly in donor recruitment and the mobilization is based on principle of restricted solidarity either in the family or friend circles and acquaintances/community members (14). Usually, these donors arrive in a group accompanied/encouraged by friends/family members. They are motivated by the belief in "giving a service" and in some way they may feel obliged to donate. Even though the donation is for the HBB and not directed to the patient him/herself, the latter is placed under a "debt of gratitude" due to his/her proximity to the replacement donors. In addition, the issue of anonymity arises in such donations since donors and patients know each other even though the donation is a replacement one (5).

Most Lebanese HBBs consider such donors as their main source to procure blood, and thus by requiring a replacement donation from the patient family - relying on replacement donations only - they place this system in a vicious circle and refrain from the switch to VNRD. Actually, some HBB try to convert some replacement donors to VNRD even in the absence of a relative in need, though with limited success as most candidates prefer awaiting that a real need is specifically addressed, thereby fuelling the vicious circle as well.

\section{The role of the Lebanese Red Cross}

The Lebanese Red Cross represents one of the largest humanitarian organizations in Lebanon and a key factor in fulfilling the blood demand for transfusion purposes. Through a 13-blood centre-network spread over the whole Lebanese territory, the Lebanese Red Cross is instrumental in the transfusion field. All centres are equipped to efficiently provide a full service in blood transfusion, from collection to processing and testing. The LCR envision 
regarding its role in the transfusion process is that each patient in need in Lebanon receives blood products timely, safely and efficiently.

The Lebanese Red Cross accounted for around $15 \%$ of the national blood supply in 2016. Meanwhile, the Lebanese Red Cross is facing the same difficulties in targeting blood donors as do HBBs. While delivering blood products components to HBBs upon request of the patient's family, the Lebanese Red Cross has to replenish the inventory and, to achieve this task, it addresses replacement donations. Actually, the majority of donations in the Lebanese Red Cross centres yet originate from family/replacement donors and not VNRD (around 9.65\%). One of the main Lebanese Red Cross objectives is to promote VNRD in order to increase their contribution to the HBBs need and to achieve a blood supply based exclusively on VNRDs. A short-term objective has been set to attain 5,000 VNRBD meaning around $25 \%$ of total donations by 2020 .

Recently, the Lebanese Red Cross lunched a blood donor recruitment form, which is an online portal where prospective voluntary donors can make an appointment to give blood at their convenience. These donors can even specify how many times per year they wish to donate. Another major goal of LRC is to increase the capacity of blood centres for welcoming blood donors. Therefore, it sought to set up unique units, dedicated exclusively for donor recruitment. Next, the LRC is currently implementing a quality management organization to optimize, among other tasks, the coordination with health care facilities. The LCR is eager to alleviate the psychological burden put on patients' families begged to bring replacement donations.

\section{The role of nongovernmental organizations: the case of the "Donner Sang Compter" Association}

Without a specific need, Lebanese citizens remain reluctant to donate blood and ignore the media demand, which is a very serious issue. To overcome this negative attitude, a nongovernmental organization was established 12 years ago with the goal to help meeting all blood demands, and goes by the name "Donner san Compter" (DSC) with the aim of creating a network of voluntary donors willing to freely give blood around the clock throughout the year. Donor identities are kept strictly confidential through the call centre to preserve privacy and anonymity and to avoid social or financial coercion. This network of voluntary donors is supposed to be efficient even in cases of over-demand. However, it is currently overstressed as not only $\mathrm{HBBs}$ but also Lebanese citizens rely more and more on DSC. While the patient family used to procure, for example, four out of five needed blood units and rely for the fifth on DSC, it is not unusual currently that family ask DSC to provide all needed $\mathrm{BCs}$ instead of complementing the missing one of five. It is acknowledged that DSC substitutes for replacement donors; this nevertheless weakens the global inventory as it is clearly not enough: DSC is only fulfilling $30-40 \%$ of its current demand and the cooperation of all stakeholders is thus highly needed.
The DSC started recruiting donors on social media where most young potential donors are active. In addition, numerous blood drives were conducted in partnership with HBBs all over the year in many public places such as universities, shopping malls, business premises in order to increase their inventory and ultimately decrease the burden placed on patients' to provide blood units/donors. Awareness campaigns and events were also conducted in these public places in order to increase the donor's database and to dispel some of the many misconceptions surrounding blood donation in Lebanon. DSC donors are genuine VNRDs donating anonymously and motivated only by the donation experience in contrast to the replacement donor.

DSC considers that even if blood components are regularly reachable, the problem consists of the stress burden that affects the whole system with specific pressure on hospitals, families and donors. Moreover, the DSC faces some serious problems such as discrepancies between $\mathrm{HBBs}$ regarding guidelines and eligible criteria for donating; waiting times are too long in some facilities due to organizational issues, and if the first donation experience has not been successful, then donors may be reluctant to take part in future donations. Thus, the DSC is currently focusing its practice on the donation experience by providing a comfortable air-conditioned bus, certificates, entertaining videos while donating and memorabilia (information leaflets, stickers, memory card, bracelets, etc.) to signify their affiliation with belonging to donor groups.

In summary, DSC believes that further collaboration with HBBs is needed as well as a merger with other NGOs to create a national Federation for blood donors supervised by the MoPH. Another suggestion would be the development of quality management system including collect donors' feedback and complaints in order to improve donor satisfaction and thus maintain regular donation.

\section{Specifics with the Shiite community: the "Ashoura" donation experience}

Lately, the Shiite community has been working to improve the image of Ashoura by discouraging practices of self-flagellation and having surrogate gestures in mourning towards making blood donation. Self-flagellation is the traditional commemoration of mourning the murder of the imams Hassan and Hussein; having worshippers inflicting self-bleeding commemorates in particular the 1oth day of this annual celebration. A considerable change regarding this ritual was made in 2009 when one of the most respected Ulama in the Shiite community encouraged the replacement of self-flagellation with voluntarily donation. However, in 2009, a major hospital (affiliated to the Shiite community) faced an emergency situation precisely on the 1oth day of Ashoura and the HBB was mobbed by dozens of donors. With the help of the nursing staff, the HBB collected around 130 donations but still could not manage to have them volunteers donating. Since then, the 1oth day of Ashoura became an opportu- 
nity to donate spontaneously in the Shiite community at this hospital. This experience raised awareness regarding the impact of religious motivation in this hospital administration; it was then considered that year long regular offerings of donating blood would better meet the demand (such as specific occasions, Friday prayers, etc.). These strategies have had a significant impact on the supply of the relevant HBBs.

\section{The Lebanese army blood bank: role and responsibilities}

The Lebanese Army holds one of the biggest HBBs in Lebanon, which collects around 10,000 blood donations per year. From the Army's point of view, other problems exist such as:

1. A lack of national transportation procedures to ensure the safety of blood products;

2. A lack of efficient and trustable networks among HBBs for exchanging blood units.

Consequently, the quality and safety of blood products issued by the Lebanese Army to health care facilities to transfuse hospitalized soldiers/families is exposed. In addition, as some of these facilities tend to repeat all screening tests, the financial burden over the health care system is increased. The vast majority of donors with the Army HBB are soldiers agreeing to donate blood "voluntarily" as a national duty and part of their commitment to the army. The donor recruitment is driven by the demand of specific blood groups. Those who donate can receive as compensatory day off, or a reimbursement of transportation costs if any, as well as a moderate fee to cover meal expenses; this is collectively aimed at manifesting gratitude. Thus, soldiers cannot donate whenever they want but only when they are requested to, which depends on the demand. Soldiers usually donate twice a year. Anonymity between donor and recipient is guaranteed.

Most of army donors are males, aged 18 to 40 and originate from the very many confessions. The Army meets all blood demands for Lebanese soldiers and families. The Army stands as a model of integration of donation by all religious groups and a standard for regular donation outside of the replacement donation within communities.

\section{Availability and safety of blood during humanitarian emergency management}

Managing blood donation during emergency situations started raising discussions in scientific communities especially after the September 11, 2001 attacks in New York, where only few units were transfused while several thousand had to be lately disposed of. This experience contributed significantly to the improvement of blood management during humanitarian emergencies. Similar situations were also reported three years later during the Madrid train attack and in France during the 2015 winter and autumn terrorist attacks (15-17). As one can notice, the majority of injured people during terrorist attacks or natural disasters either dies before arriving to the hospi- tal or has superficial injuries and don't need transfusion.

As for Lebanon, the 2006 war experience and the last terrorist incident on 12 November 2015, (where respectively $15 \%$ and $24 \%$ of injured civilians were transfused), call for two commentaries: First, the percentage of injured people needing transfusion was higher compared to Western tragedies, perhaps because of the nature of injuries and weapons. Second, the number of collected units is almost the same as to those actually transfused; this demonstrates that management of blood collection was adequate, at least for the moment. Indeed, in the South Eastern suburban of Beirut (where last terrorist incident took place) there are five middle size hospitals complying with a local emergency preparedness plan, which consists in having a target minimal stock of blood and applying an efficient networking blood supply system. This plan has proven its efficacy since blood was available for all injured patients.

Based on these two Lebanese experiences, numerous challenges during emergency situations were identified as follow:

- To face a war situation: it is essential to procure blood for fighters or soldiers on the battlefield even when the infrastructure has collapsed and to cope with an increasing demand merging both an influx of injured people and loss of donors at the same time.

- To face a terrorist attack: it is essential to maintain an adequate stock of blood products, organizing accurate schedules for the on-call staff in order to be able to absorb the influx of donors, and organize a network for adequate transportation between nearby healthcare facilities.

Consequently, it is now central to conduct a study in order to define the needed inventory in case of terrorist attack (based on previous experiences) and how to avoid spillage. Furthermore, a "media coordinator" available in case of casualties is needed to assign donors to the diverse healthcare facilities or re-orientate them, and to eventually stop the rush once enough blood is collected. Not only donor candidacies are the problem to be solved but also the logistics to collect them according to the needs, both in terms of devices, goods and human resources.

Of particular note concerning those dramatic events was the fact that the Lebanese donate voluntarily and massively in emergency situations reflecting a sense of national solidarity. The challenge is how to manage the rush of donors in such situations which would demand an efficient network between HBBs and organizations (Lebanese Red Cross, Army, NGOs ...) to collect optimally.

However, when looking back to the impact of emergency donations on the sustainability of blood supply, the studies carried out in Lebanon (2006 war), USA (11th September) (18) and Iran (earthquake 2009) (19), show a common feature which is a low return rate when the situation returns to normal. This means that most first time, occasional, donors will not return, irrespectively of culture. Further, HBBs in Lebanon also learnt that those donors upon arrival in the facility express some reluctance to comply with the situation is not perceived 
as exceptional (e.g. chronic patient with a need for platelet) if the need for emergency has been fulfilled. This echoes well with what was observed in the USA after the September 112001 attack, the American Association of Blood Banks (AABB) director stated at that time that the current issue was no longer the availability of sufficient blood donors, but disruption to the blood supply system itself. Consequently, in Lebanon there is a still need to combat the misconception of donating voluntarily only in the emergency circumstances by educating people and introducing the values of voluntary donation.

\section{Relevant questions (Background)}

In order to improve safety in TM and to achieve a safe, reliable and sustained national blood supply, the Lebanese authorities represented by $\mathrm{MoPH}$ established the LNCBT in 2011 and contracted during the same year the French blood facility Établissement Français du Sang (EFS) to assist this committee in addressing this task. The agreement was arranged through the Beirut-based French-Lebanese Business School, Ecole Supérieure des Affaires (ESA). Since then, despite the several advancements made over years regarding blood processing/ testing and safety (see below), the issues of achieving a VNRD-based recruitment and ensuring nationwide sufficiency have still not been met.

Lebanon is a country which has suffered civilian and military strife over the past decades, preventing the creation of a reliable and uniform healthcare organization nationwide; furthermore, Lebanon relies mainly on a private sector economy, and the current status of the blood supply in Lebanon is mainly based on replacement/family donors overseen by HBBs for their own internal use (5); this clearly does not fulfill WHO recommendations. Hence, two important questions need to be addressed: 1) how can such a decentralized system progress in making a blood supply capable of meeting the demand?; and 2) what would be the most important steps to address? In parallel to the joint collaborative and practical program with EFS, an academic investigation has been launched with the National Institute for Blood transfusion in Paris, France (INTS) in collaboration with the University of Lyon/Saint-Etienne. The latter program is aimed at addressing epidemiological and sociological issues to better understand Lebanon's needs in blood supply and transfusion safety. The program has been expanded to all countries of the Maghreb and Levant (20).

\section{World blood donor day celebration: an opportunity to cease to engage discussions}

The LNCBT took the opportunity of celebrating World Blood Donor Day (WBDD), 14 June 2017, to host a half day seminar and organize round table discussions involving all main stakeholders of the blood donation process in Lebanon. Each year since 2004, and upon the invitation of WHO, one country is chosen as the official celebration host and a slogan is released, aimed at attracting the attention of populations and country health authorities. In
2017, the host country was Vietnam and the action slogan was: "What can you do? Give blood. Give now. Give often." (21). This was felt to be a great opportunity for one Beirut hospital through its HBB to host this national seminar in order to: 1) spread awareness for the need of safe blood and blood products; 2) thank blood donors for their life-saving blood gifts; 3 ) promote regular donations; and 4) make it visible nationwide. It was also a great opportunity to explain nationwide why donating is crucial because blood products have expiry dates, imposing a regularly renewed inventory to avoid blood shortage.

The event's more specific aims were also: 1) to enlist the current types of donations in the country;2) to discuss reciprocal advantages and disadvantages; 3) to identify the main roadblocks in achieving a VNRD-based blood supply; and 4) to draft a consensus-based road map that can be forwarded to the MoPH. The long-term objective of this seminar was to help the MoPH to take actions in favor of a more generalized VNRD in the country.

\section{Moving forward in improving the transfusion process: the MoPH's project}

The MoPH is responsible by law for the efficient supply of blood products and for the overall quality, safety, availability and equitable distribution of these products. This task is particularly difficult to achieve in the absence of a well-organized national blood transfusion service governed by a national public health policy (WHO recommendations) (10). The MoPH director advised by French experts/LNCBT has identified that at a minimum, a quality and safety system should oversee good transfusion practices in the whole chain, including blood grouping, compatibility, viral screening and processing, standardization of donor selection and reporting system. This was assigned to LNCBT. Next, the LNCBT should consider the promotion of VNRD (difficult to achieve because of the absence of human resources in the Ministry) and setting up of patient blood management and optimal blood use programs.

SeveralactionswereundertakenbytheMoPH,delegated to LNCBT in collaboration with ESA/ EFS (11), specifically: 1) the development of good transfusion practices (2012); 2) the introduction of additional safety measures such anti-HBc screening and universal leukoreduction (2013) applicable to every HBB processing blood components; 3 ) the release of software requirement specifications for $a$ HBB management system (2014); and 4) the progressive development of a national haemovigilance program (as of 2015), that comprises a national blood donor questionnaire, the definition of blood donor selection criteria, the release of pre- and post-donation information leaflets, the setup of a transfusion related adverse reaction notification form and of donors' adverse reactions reporting form. These documents are released on the MoPH website but HBBs are not yet inspected (22).

On June 14, 2016, the first national campaign for the promotion of VNRD was launched at ESA location in the presence of the MoPH and the media. The campaign was disseminated in three languages (French, English 
and Arabic) through video TV ads, radio, billboards and posters. A hotline number "1214" was also settled to direct motivated donors towards the nearest blood centers.

The MoPH is well aware that those actions were not sufficient to meet the WHO goals regarding 100\% VNRD. It aims at further elaborating strategies for strengthening applicable laws and organizing orientation/educational sessions for $\mathrm{HBB}$ professionals. The $\mathrm{MoPH}$ is now considering implementing a national certification program for blood transfusion centers and a national procedure/network transportation system for blood products, despite political and economic struggles.

\section{Road blocks to achieving $100 \%$ voluntary blood donation}

All stakeholders met to reflect on blood donation and collection in Lebanon, and taking into consideration peace and wartime, and identified a number of roadblocks preventing a safe and sustainable inventory, as follows:

1. Culturally, the Lebanese expect some form of benefit from donating blood and more specifically if the patient is outside their family and friend or relative circles. One of their commonest replies when asked to donate blood is "What's in it for me?"

2. Donating is costly and time consuming because of frequent traffic jams in the city and the remoteness of the HBBs, which in addition do not operate after hours when traffic has eased. Donors would thus need or request time off just to donate. Moreover, free-of-charge parking and the post-donation canteen are not available in all HBBs.

3. Blood transfusion is not considered a public health issue; hence, a strict control, supervision, and inspection by Lebanese national authorities is lacking. The government may consider delegating to organizations such as the Lebanese Red Cross while providing financial support and overseeing their activities.

4. There are still Lebanese not aware about when and how to donate voluntarily, which calls for widespread information campaigns. It will also help to dispel some of the misconceptions regarding blood donation such as fears of harm to their health (ranging from fear of needles to loss of virility in males) or that receiving blood from family members or friends is safer and will eliminate the risk of transfusion-transmissible infection.

5. Laboratory workers do not possess a sufficient understanding of the psychology of people in order to attract and retain volunteer blood donors; they need specific education on how to improve their personal skills.
6. Staffing also poses a problem that range from a mild deficit in $\mathrm{HBB}$ technologists to the complete absence of donor recruiters. The latter must be enthusiastic and competent, not necessarily from medical or HBB background, but possesses an ability to lead and persuade. However, such positions are often not regarded highly by administrators nor have financial incentives/salaries. In fact, these are seen as a waste of resources and attention is often directed towards buying sophisticated technical equipment rather than upgrading and adequately staffing a donor system. Other difficulty related to staffing is that most laboratory and HBB directors are not adequately trained in transfusion medicine and only a few had direct experience or training in blood donor recruitment. Much more effort needs to be directed to ensure that HBB directors are fully informed on different methods of donor recruitment and motivation.

\section{Concluding perspectives}

- The MoPH should focus on performing regular inspections/audits regarding the implementation of all available national guidelines, and especially those which might affect the experience and retention of donors such as good practice for phlebotomy and blood donor selection criteria.

- A need for a blood supply committee under the auspices of the MoPH that would reunify all stakeholders in the blood transfusion and donation fields. Its mission would be (among others): 1) to provide an audit on the current situation; 2) to promote VNRD through campaign media and education; 3) to promote a successful network between LRC, NGOs, the Army and HBBs; 4) to elaborate preparedness plans for emergency situations; 5) to approach ethical issues related to donors and donations; 6) to implement a national data system management and to make possible the establishment of a national blood donor card; 7) to develop regular blood drives; and 8) to support scientific forums and seminars and education initiatives on blood donation and supply.

- Further roles for the MoPH have been proposed, including allocating adequate resources to this blood supply committee. MoPH should also be further engaged in the improvement process of transfusion activities in general, and transfusion medicine should be declared by law as a public health issue and should be considered a national priority for patient safety especially in critical situations.

\section{Acknowledgements}

A Haddad, MD, attends a PhD programme with the University of Saint-Etienne and he wishes to acknowledge Ecole Supérieure des Affaires, Beirut, Lebanon, Etablissement Français du Sang and Institut National de Transfusion Sanguine, France, for their support as well as the University of Lyon-Saint-Etienne. The PhD programme is supported in part by grants from the Association Recherche Transfusion, Paris, France.

Funding: None.

Competing interests: None declared. 


\section{Difficultés à assurer un approvisionnement en sang durable : compte rendu du premier séminaire national sur le don de sang au Liban}

\section{Résumé}

Contexte : Le Liban dispose d'un système de transfusion décentralisé et fragmenté. L'approvisionnement en sang actuel ne répond pas à l'objectif de l'Organisation mondiale de la Santé, à savoir atteindre $100 \%$ de dons de sang volontaires et non rémunérés. Actuellement, il existe trois types de donateurs/dons au Liban : dons de compensation/familiaux (70-75\%), dons de sang volontaires et non rémunérés (20-25\%) et dons compensés (5-10\%). Les dons rémunérés sont illégaux.

Objectifs : Le présent compte rendu résume le contenu des présentations effectuées lors du premier séminaire ayant eu lieu au Liban en juin 2017 à l'occasion de la Journée mondiale du donneur de sang. L'objectif était de décrire le système d'approvisionnement en sang en place au Liban ainsi que les principaux obstacles associés, et de suggérer des recommandations pratiques susceptibles d'aider à atteindre l'objectif de $100 \%$ de dons de sang volontaires et non rémunérés.

Méthodes : Le contenu des présentations effectuées lors du premier séminaire ayant eu lieu au Liban en juin 2017 à l'occasion de la Journée mondiale du donneur de sang a été résumé.

Résultats : Les principaux partenaires impliqués dans la médecine transfusionnelle ont assisté au séminaire (Comité national libanais de transfusion sanguine, directeurs des banques de sang des hôpitaux, banque de sang de l'armée du Liban, Croix-Rouge libanaise et Donner Sang Compter).

Conclusions : Le ministère de la Santé publique devrait se concentrer sur la réalisation des vérifications régulières concernant l'application des lignes directrices nationales. Il est nécessaire de mettre en place un comité national pour l'approvisionnement en sang rassemblant tous les partenaires impliqués dans la transfusion et le don de sang. La médecine transfusionnelle devrait être déclarée par la loi comme une question de santé publique et considérée comme une priorité pour la sécurité des patients.

$$
\begin{aligned}
& \text { صعوبات تواجه تحقيق إمدادات مستدامة بالدم: تقرير صادر عن الحلقة الدراسية الوطنية الأولى حول التبرع بالدم في لبنان }
\end{aligned}
$$

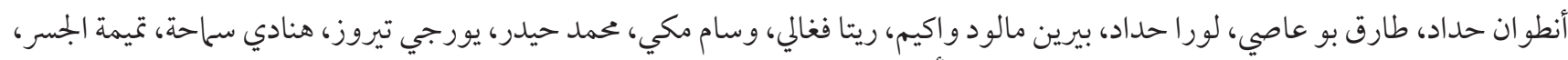

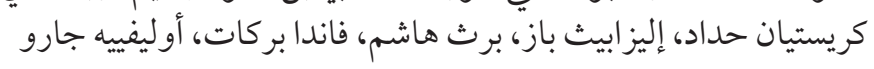

الخلفية: يتسم نظام نقل الدم في لبنان باللامركزية أو التفتّت. ولان تتو اءم الإمدادات الحالية من الدم بما تستهدفه منظمة الصحة العالمية من تحقيق

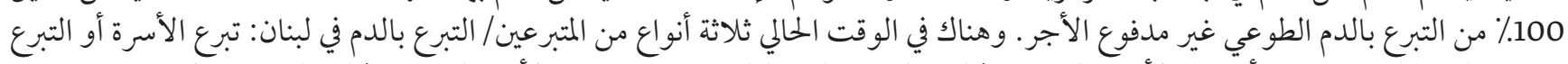

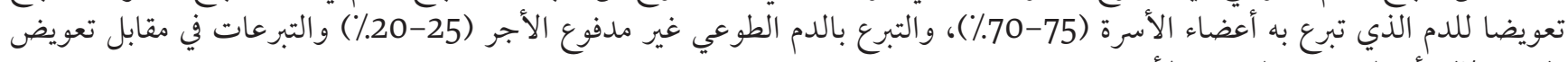

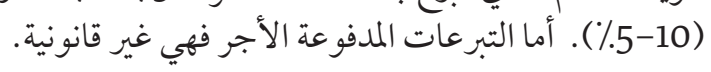

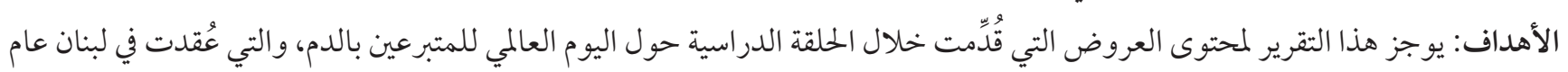

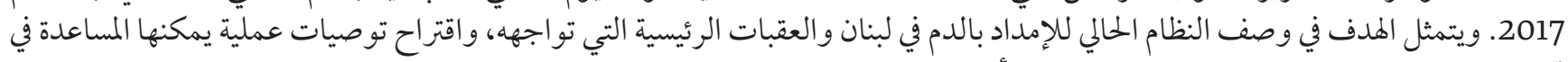

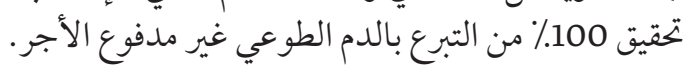

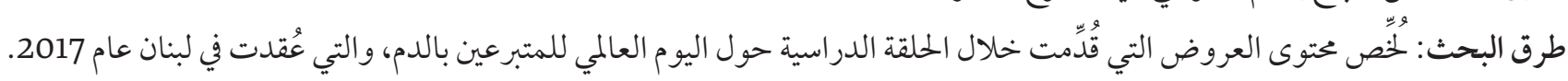

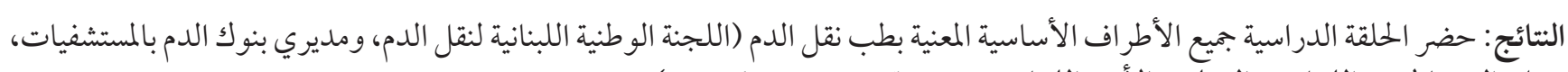

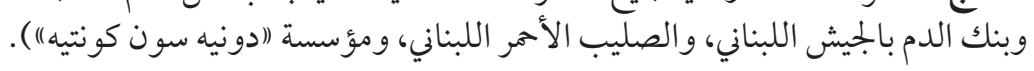

الاستنتاجات: يجب على وزارة الصحة العامة إيلاء التركيز إلى إجراء مر اجعات منتظمة بشأن تنفيذ المبادئ التو جيهية الوطنية. وهناك حاجة إلى إلى إلى إنشاء

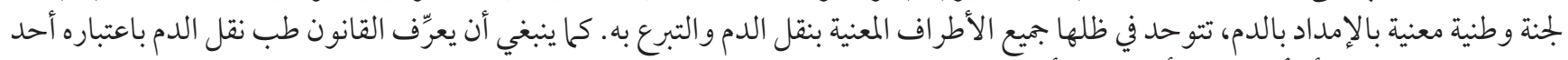

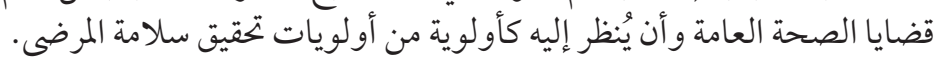

\section{References}

1. Garraud O, Tissot J-D, Osselaer J-C, Folléa G, Vernant J-P, Lefrère J-J. Transfusion safety from the viewpoint of a musical quintet. Blood Transfusion. 2015;13(4):687. https://doi.org/10.2450/2015.0297-14.

2. Sadana D, Pratzer A, Scher LJ, Saag HS, Adler N, Volpicelli FM, et al. promoting high-value practice by reducing unnecessary transfusions with a patient blood management program. JAMA Intern Med. 2018 Jan 1; 178(1):116-122. https://doi.org/10.1001/ jamainternmed.2017.6369 
3. Kohne E. Hemoglobinopathies: Clinical manifestations, diagnosis, and treatment. Deutsches Ärzteblatt International. 2011;108(31-32):532-40. https://doi.org/10.3238/arztebl.2011.0532.

4. WHO Expert Group. Expert consensus statement on achieving self-sufficiency in safe blood and blood products, based on voluntary non-remunerated blood donation (VNRBD). Vox Sang. 2012 Nov;103(4):337-42. https://doi.org/10.1111/j.14230410.2012.01630.x.

5. Haddad A, Bou Assi T, Garraud O. Can a decentralized blood system ensure self-sufficiency and blood safety? The Lebanese experience. J Public Health Policy. 2017;38:359-65. https://doi.org/10.1057/s41271-017-0076-x.

6. Regional meeting of directors of blood transfusion services. Alexandria: World Health Organization, Regional office for the Eastern Mediterranean; 2000 (http://applications.emro.who.int/docs/who_em_lab_327_e_l_en.pdf, accessed 27 August 2018).

7. The Melbourne Declaration on 100\% Voluntary Non-Remunerated Donation of Blood and Blood Components. Geneva: World Health Organization; 2009 (http://www.who.int/worldblooddonorday/MelbourneDeclarationWBDDo9.pdf, accessed 04 January 2018).

8. Strategic Framework for Blood Safety and Availability 2016-2025. Cairo: World Health Organization, Regional Office for the Eastern Mediterranean; 2016 (http://www.who.int/iris/handle/10665/250402, accessed 25 January 2018).

9. The Lebanese constitution. Beirut: Presidency of the Republic of Lebanon; 1926 (http://www.wipo.int/edocs/lexdocs/laws/en/lb/ lbo18en.pdf, accessed 03 September 2017).

10. Blood safety. Geneva: World Health Organization; 2014 (http://www.who.int/bloodsafety/transfusion_services/en/Blood_Safety_Eng.pdf?ua=1/, accessed 14 January 2018).

11. Recueil national des statistiques sanitaires au Liban. Beirut: Institut de Gestion de la Santé et de la Protection Sociale; 2016 (http://www.igsps.usj.edu.lb/docs/recherche/recueilıfr.pdf/, accessed 8 December 2017).

12. Haddad A, Bou Assi T, Ammar W, Baz E. Does a liberal national transfusion law assure blood safety? A survey of blood bank directors perspectives in Lebanon. J Public Health Policy 2013; 34(4): 515-27 (https://doi.org/10.1057/jphp.2013.33.

13. Act 766 published on 16/11/2006 in the Lebanese Official Journal. Beirut: Lebanese Government; 2006 (http://www.pcm.gov.lb/ arabic/subpgoldJo.aspx?pageid=3836, accessed 01 February 2018).

14. Titmuss, R. The gift relation ship: from human blood to social policy. London: Penguin Books Ltd; 1973.

15. Korcok M. Blood donations dwindle in US after post-Sept. 11 wastage publicized.: Canadian Med Assoc J. 2002;167(8):907. PMID:12406957

16. De Ceballos JPG, Turégano-Fuentes F, Perez-Diaz D, Sanz-Sanchez M, Martin-Llorente C, Guerrero-Sanz J. 11 March 2004: The terrorist bomb explosions in Madrid, Spain - an analysis of the logistics, injuries sustained and clinical management of casualties treated at the closest hospital. Critical Care. 2005;9(1):104-111. https://doi.org/10.1186/cc2995.

17. Tresson P, Touma J, Gaudric J, Pellenc Q, Le Roux M, Pierret C, Kobeiter H et al. Management of vascular trauma during the Paris terrorist attack of November 13, 2015. Ann Vasc Surg. 2017;40:44-9. https://doi.org/10.1016/j.avsg.2016.09.011.

18. Glynn SA, Busch MP, Schreiber GB, Murphy EL, Wright DJ, Tu Y, et al. Effect of a national disaster on blood supply and safety: the September 11 experience. JAMA. 2003 May 7;289(17):2246-53. https://doi.org/10.1001/jama.289.17.2246

19. Abolghasemi H, Radfar MH, Tabatabaee M, Hosseini-Divkolayee NS, Burkle FM Jr. Revisiting blood transfusion preparedness: experience from the Bam earthquake response. Prehosp Disaster Med. 2008 Sep-Oct;23(5):391-4. PMID:19189607

20. Haddad A, Bou Assi T, Garraud O. How can eastern/southern Mediterranean countries resolve quality and safety issues in transfusion medicine? Front Med. 2018;5:45. https://doi.org/10.3389/fmed.2018.00045

21. World Blood Donor Day. Geneva: World Health Organization; 2017 (http://www.who.int/campaigns/world-blood-donorday/2017/event-announcement-english.pdf?ua=1, accessed 04 February 2018).

22. Blood Transfusion. Beirut: Republic of Lebanon, Ministry of Public Health; 2015 (http://www.moph.gov.lb/en/Pages/4/3262/ blood-transfusion-\#/en/Pages/4/3262/blood-transfusion, accessed 07 January 2018). 